CORIGINAL ARTICLE

Volume 15 Issue 12020

DOI: 10.21315/aos2020.15.1.411

ARTICLE INFO

Submitted: 08/01/2020

Accepted: 08/06/2020

Online: $15 / 07 / 2020$

\section{CYP3A4*18 and CYP3A5*3 Polymorphisms in Modulating Susceptibility Risk in Malaysian Chronic Myeloid Leukaemia Patients}

\author{
Najlaa Maddina, Azlan Husin ${ }^{\mathrm{b}}$, Baba Abdul Azizc, Ravindran Ankathil ${ }^{*}$ \\ ${ }^{a}$ Human Genome Centre, School of Medical Sciences, Universiti Sains \\ Malaysia, 16150 Kubang Kerian, Kelantan, Malaysia \\ ${ }^{b}$ Haemato-Oncology Unit E Department of Internal Medicine, \\ School of Medical Sciences, Universiti Sains Malaysia, \\ 16150 Kubang Kerian, Kelantan, Malaysia \\ 'International Medical University Malaysia, Kuala Lumpur, \\ 57000 Bukit Falil, Wilayah Persekutuan Kuala Lumpur, Malaysia \\ *Corresponding author: rankathil@hotmail.com
}

To cite this article: Maddin $\mathrm{N}$, Husin A, Aziz BA, Ankathil $\mathrm{R}(2020) . C Y P 3 A 4^{\star} 18$ and $C Y P 3 A 5^{\star} 3$ polymorphisms in modulating susceptibility risk in Malaysian chronic myeloid leukaemia patients. Arch Orofac Sci, 15(1): 23-33. https://doi.org/10.21315/aos2020.15.1.411

To link to this article: https://doi.org/10.21315/aos2020.15.1.411

\begin{abstract}
CYP3A4 and CYP3A5 are metabolizing enzymes abundantly expressed in liver and involved in the metabolism of xenobiotics as well as clinically used drugs. Genetic polymorphisms in $C Y P 3 A 4$ and CYP3A5 may alter the metabolic ability of individuals. Thus, CYP $3 A 4$ and CYP $3 A 5$ might play an important role in the aetiology of chronic myeloid leukaemia (CML) and as modulators of cancer therapy response. In this study, the impact of two single nucleotide polymorphisms (SNPs) CYP $3 A 4^{\star} 18$ $(878 \mathrm{~T}>\mathrm{C})$ and $C Y P 3 A 5^{\star} 3(6986 \mathrm{~A}>\mathrm{G})$ on $\mathrm{CML}$ susceptibility risk was investigated. This case-control study involved a total of 520 study subjects comprising 270 CML patients and 250 normal healthy controls. Genotyping of $C Y P 3 A 4^{\star} 18$ and $C Y P 3 A 5^{\star} 3$ was performed by polymerase chain reaction restriction fragment length polymorphism (PCR-RFLP) technique. The association between allelic variants and CML susceptibility risk was assessed by logistic regression analysis, deriving odds ratio (OR) with $95 \%$ confident intervals. The results showed that heterozygous $\left({ }^{\star} 1 /{ }^{\star} 1{ }^{\star} 8\right)$ genotype of CYP $3 A 4^{\star} 18$ was significantly associated with CML susceptibility risk (OR 3.387; 95\% CI: $1.433-8.007$, $\mathrm{p}=0.005)$. No homozygous variant $\left({ }^{\star} 18 /{ }^{\star} 18\right)$ genotype was detected in this study. On the contrary, homozygous variant $\left(\star^{\star} /{ }^{\star} 3\right)$ and heterozygous $\left({ }^{\star} 1 /{ }^{\star} 3\right)$ genotypes of $C Y P 3 A 55^{\star} 3$ were associated with significantly lower risk for CML susceptibility (OR 0.140; 95\% CI: $0.079-0.246^{\prime} \mathrm{p}<0.001$ and OR 0.310 ; $95 \%$ CI: $0.180-0.535, \mathrm{p}<0.001$, respectively). The results prompt us to conclude that genetic variation in $C Y P 3 A 4^{\star} 18$ may contribute to a higher risk whereas $C Y P 3 A 5^{\star} 3$ polymorphism confers a lower susceptibility risk in Malaysian CML patients.
\end{abstract}

Keywords: $C Y P 3 A 4^{\star} 18$; $C Y P 3 A 5^{\star} 3$; polymorphisms; chronic myeloid leukaemia; susceptibility risk 


\section{INTRODUCTION}

Chronic myeloid leukaemia (CML), a myeloproliferative neoplasm, is characterised by the Philadelphia (Ph) chromosome, resulting from a reciprocal translocation between chromosomes 9 and $22 \mathrm{t}(9: 22)$ (q34;q11) (Al-Achkar et al., 2013). Philadelphia translocation $t(9 ; 22)$ (q34;q11) is detected in $95 \%$ of $\mathrm{CML}$ cases (Zheng et al., 2009). This reciprocal $t(9: 22)$ translocation transfers the Abelson (ABL) proto-oncogene on chromosome 9 to the breakpoint cluster region (BCR) of chromosome 22, resulting in the formation of a $B C R-A B L$ fusion gene (Al-Achkar et al., 2013), which functions as an oncogene. $B C R-A B L$ fusion gene encodes for a 210 $\mathrm{kDa}$ protein with increased tyrosine kinase activity. The dysregulated tyrosine kinase activity of $B C R-A B L$ fusion gene is responsible for the pathogenesis of CML. CML comprises $15 \%-20 \%$ of all adult leukaemias, with a median age of diagnosis of 50 years (Rumjanek et al., 2013), and rarely occurs in children. Among childhood leukaemias, CML is a rare entity with an annual incidence of one case per million children (Nikumbh et al., 2012).

The risk factors for CML are still unclear. Exposures to radiation or radiation therapy, previous chemotherapy for other types of cancer, long term exposure to high levels of environmental carcinogens such as benzene 1-3 butadiene, dioxin, and metals have all been implicated as risk factors for CML. However, not all individuals exposed to these risk factors do develop CML. Furthermore, a few earlier studies (Biernaux et al., 1995; Bose et al., 1998) had demonstrated the presence of very low levels of $B C R$ $A B L$ fusion gene in the blood of healthy people, but who never developed CML. All the above facts reiterate that $B C R-A B L$ fusion gene is essential, but not sufficient for the development of CML. Additional predisposing factors, such as host's inherent susceptibility factors might also be important in the development of CML.
Cytochrome P450 (CYP) plays an important role in the bio-activation and inactivation of carcinogens and participates in the activation and inactivation of anticancer drugs. Thus, CYP may play an important role, both in the aetiology of cancer and in the modulation of cancer therapy response. CYP3A subfamily is the most abundantly expressed P450 protein in the human liver and intestine and is the predominant subfamily involved in the metabolism of clinically used drugs as well as environmental carcinogens. The two major $C Y P 3 A$ enzymes expressed in the liver are $C Y P 3 A 4$ and $C Y P 3 A 5$.

Common allelic variation in the form of single nucleotide polymorphisms of CYP3A4 are known to affect the catalytic activity. A common $C Y P 3 A 4^{\star} 18$ polymorphism located in the exon 10 of $C Y P 3 A 4$, involves nucleotide change from tyrosine $(\mathrm{T})$ to cytosine (C) transition at position 878 and results in amino acid change leucine to proline at codon 293 (Leu293Pro) (Hu et al., 2005; Seong et al., 2013). This polymorphism $C Y P 3 A 4^{\star} 18(878 \mathrm{~T}>\mathrm{C})$ leads to altered enzymatic activity. $C Y P 3 A 5$ which is located on chromosome $7 \mathrm{q} 21.1$, exhibits inter-individual variations in expression levels. A polymorphism of $C Y P 3 A 5^{\star} 3$ located in the intron 3 of $C Y P 3 A 5$ involves nucleotide change from adenine (A) to guanine (G) transition at position 6986. Polymorphism CYP3A5*3 (6986 A > G) produces a cryptic splice site and encodes for an abnormally spliced mRNA with a premature stop codon. $C Y P 3 A 5^{\star} 3$ allele can reduce the expression of $C Y P 3 A 5$ which leads to drug toxicity and subsequent DNA damage.

Since CYP3A4 and CYP3A5 are mostly involved in the metabolism of tyrosine kinase inhibitor drug imatinib mesylate, the gold standard drug in the treatment of CML, our group previously investigated the impact of these two single nucleotide polymorphisms (SNPs) in modulating response to imatinib treatment in Malaysian CML patients (Maddin et al., 2016). SNPs are genetic 
variations that also modulate (increase or decrease) the risk of certain diseases including cancer. Individual variations in metabolism of carcinogens account for the differences in susceptibility to cancer and could be an attributable risk factor. Casecontrol study can detect differences in SNPs pattern in two groups (cases and controls) and thereby indicate which pattern is most likely associated with higher or lower disease-causing risk. So, as further extension of our previous study, it was of interest to investigate whether these two SNPs modulate the susceptibility risk to CML. Hence, this case-control study (involving CML patients as cases and normal healthy individuals as controls) was designed to investigate the contribution of $C Y P 3 A 4^{\star} 18$ and $C Y P 3 A 5^{\star} 3$ polymorphism in modulating susceptibility risk in Malaysian CML patients.

\section{MATERIALS AND METHODS}

\section{Subjects and DNA Extraction}

This case-control study was approved by the Human Research Ethics Committee of Universiti Sains Malaysia (USMKK/PPP/ JEPeM [244.3.(4)]) and Ministry of Health, Malaysia (KKM/NHSEC/08/0804/P12687) which complies with the declaration of Helsinki. The cases were $\mathrm{Ph}$ chromosome positive CML patients. The normal controls were healthy volunteers without any signs and symptoms of CML or any other cancer and biologically unrelated to the cases. Subjects were recruited from various hospitals in Malaysia including Hospital Universiti Sains Malaysia, Hospital Raja Perempuan Zainab II, Hospital Pulau Pinang, Hospital Raja Permaisuri Bainun, Universiti Kebangsaan Malaysia Medical Center, Sime Darby Medical Centre and Hospital Umum Sarawak. In this study, a total of 520 study subjects comprising 270 CML patients and 250 normal healthy controls were enrolled.
Peripheral blood $(3 \mathrm{ml})$ was collected after obtaining written informed consents from all the study subjects. Genomic DNA was extracted using a DNA extraction kit, QIAGEN QIAamp ${ }^{\circledR}$ DNA Blood Mini kit (QIAGEN, Hilden, Germany) according to the manufacturer's instructions. Genotyping was conducted at Human Genome Centre, Universiti Sains Malaysia.

\section{Genotyping of CYP3A4* 18 and CYP3A5*3 Polymorphisms}

Genotyping of $C Y P 3 A 4^{\star} 18$ and $C Y P 3 A 5^{\star} 3$ polymorphisms were performed by using polymerase chain reaction - restriction fragment length polymorphism (PCRRFLP) technique. Amplification of $C Y P 3 A 4^{\star} 18$ was performed by using forward (5'-CACATCAGAATGAAACCACC3'-) and reverse (5'-AGAGCCTTCCTACATA GAGTCA-3') primers. For $C Y P 3 A 5^{\star} 3$, the primers used were 5'-GGTCCAAACAGGG AAGAAATA-3' - (forward) and 5'-CATGA CTTAGTAGACAGATGAC-3' (reverse). For both $C Y P 3 A 4^{\star} 18$ and $C Y P 3 A 5^{\star} 3$ polymorphisms, PCR reactions were carried out in a $25 \mu \mathrm{l}$ volume of $1 \mathrm{X}$ PCR Buffer, 2.0 $\mu \mathrm{M}$ of magnesium chloride $\left(\mathrm{MgCl}_{2}\right), 0.5 \mu \mathrm{M}$ dNTPs, $0.4 \mu \mathrm{M}$ of each primer and 1.0 $\mathrm{U}$ of AmpliTaq Gold Polymerase. Denaturation was at $95^{\circ} \mathrm{C}$ for $2 \mathrm{~min}$, followed by 35 cycles at $95^{\circ} \mathrm{C}$ for $30 \mathrm{~s}, 55^{\circ} \mathrm{C}$ for $30 \mathrm{~s}, 72^{\circ} \mathrm{C}$ for $30 \mathrm{~s}$ and a final extension step at $72^{\circ} \mathrm{C}$ for $5 \mathrm{~min}$. The $450 \mathrm{bp}$ PCR products of $C Y P 3 A 4^{\star} 18$ and the $293 \mathrm{bp}$ PCR product of $C Y P 3 A 5 * 3$ were electrophoresed on a $2 \%$ agarose gel at $100 \mathrm{~V}$ for $30 \mathrm{~min}$.

Following PCR amplification, $4 \mu \mathrm{l}$ of $450 \mathrm{bp}$ PCR products of $C Y P 3 A 4^{\star} 18$ were digested with 1.0 unit of a restriction enzyme $(M s p I)$ for 1 hour at $37^{\circ} \mathrm{C}$. The digested PCR products were analyzed by electrophoresis on a $2 \%$ agarose gel at $90 \mathrm{~V}$ for $50 \mathrm{~min}$ (Figure 1a). The homozygous wild type allele $\left({ }^{\star} 1 /{ }^{\star} 1\right)$ was identified by the presence of an undigested band (450 bp), while heterozygous allele $\left({ }^{\star} 1 /{ }^{\star} 18\right)$ was confirmed 
by the presence of three fragments at $450 \mathrm{bp}$, $282 \mathrm{bp}$ and $168 \mathrm{bp}$. The homozygous variant allele $\left({ }^{\star} 18 /{ }^{\star} 18\right)$ showed the presence of two fragments at $282 \mathrm{bp}$ and $168 \mathrm{bp}$.

On completion of PCR amplification of $C Y P 3 A 5^{\star} 3,4 \mu \mathrm{l}$ of PCR products were digested by restriction enzyme $S s p I$ for $15 \mathrm{~min}$ at $37^{\circ} \mathrm{C}$ (Figure 1b). The digested PCR products were analyzed by electrophoresis on a 3\% agarose gel. The homozygous wild type allele $\left({ }^{\star} 1 /{ }^{\star} 1\right.$ or AA) was identified by the presence of three bands at $148 \mathrm{bp}, 125 \mathrm{bp}$ and $20 \mathrm{bp}$ whereas homozygous variant allele $\left({ }^{\star} 3 /{ }^{*} 3\right.$ or GG) was confirmed by the presence of two fragments of sizes $168 \mathrm{bp}$ and $125 \mathrm{bp}$. The heterozygous variant allele $\left({ }^{\star} 1 /{ }^{\star} 3\right.$ or AG) was identified by the presence of four bands at $168 \mathrm{bp}, 148 \mathrm{bp}, 125 \mathrm{bp}$ and $20 \mathrm{bp}$.

\section{DNA Sequencing}

Approximately $10 \%$ of the undigested PCR products were randomly selected for DNA sequencing to confirm the polymorphic genotypes inferred from RFLP analysis (Figure 2). The PCR products were purified by using a QIAquick PCR purification kit (QIAGEN) and PCR products of sufficiently good quality and quantity were outsourced to First BASE Laboratories Sdn Bhd (Kuala Lumpur, Malaysia) for DNA sequencing.

\section{Statistical Analysis}

The frequencies of polymorphic genotypes among CML patients and normal healthy control subjects were compared by using Chi-square test $\left(\chi^{2}\right)$. The odds ratios (ORs) and 95\% confidence intervals (CIs) were calculated using a binary logistic regression to investigate the risk association of genotypes with CML susceptibility risk. All statistical tests were two sided, and statistical significance was determined as $p<0.05$. SPSS v.20.0 (SPSS Inc., Chicago, IL, United States) was utilised. Deviation of the genotypic distribution from Hardy Weinberg equilibrium (HWE) was examined by using a Chi-square goodness of fit test. (a)

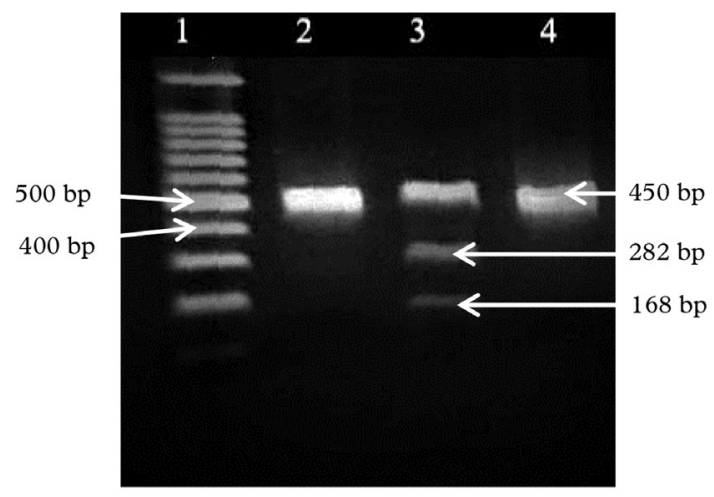

(b)

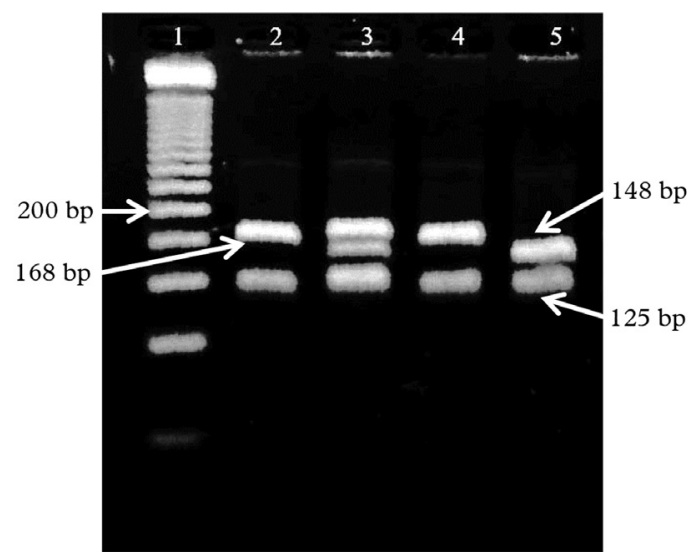

Fig. 1 Gel picture showing different genotype patterns of a CYP3A4*18 (following digestion with $M s p l$ ) and $\mathbf{b}$ CYP3A5*3 (following digestion with Sspl). a Lane 1 shows a 100 bp ladder. Lanes 2 and 4 shows a homozygous wild type genotype. Lane 3 indicates a heterozygous genotype. $\mathbf{b}$ Lane 1 shows 50 bp ladder. Lanes 2 and 4 indicates homozygous variant genotype. Lane 3 indicates heterozygous genotype. Lane 5 shows homozygous wild type genotype.

\section{RESULTS}

The genotypic distribution of the two polymorphisms among the control did not deviate significantly from HWE, $p>0.05$ (Table 1). All subjects (270 CML patients and 250 normal healthy controls) were successfully genotyped by PCRRFLP technique. The genotype frequencies and the association of $C Y P 3 A 4^{\star} 18$ and $C Y P 3 A 5 * 3$ polymorphisms with $\mathrm{CML}$ susceptibility risk are shown in Table 2 and Table 3, respectively. In this study, no homozygous variant $\left({ }^{\star} 18 /{ }^{\star} 18\right)$ genotype was 
(a)

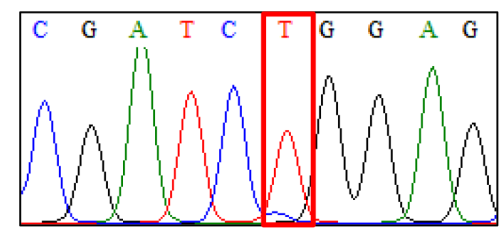

(i)

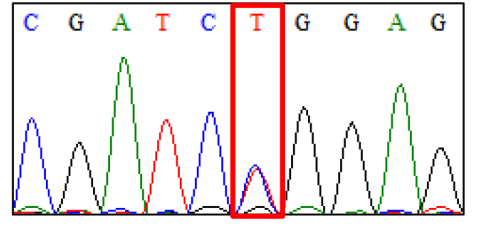

(ii)

(b)

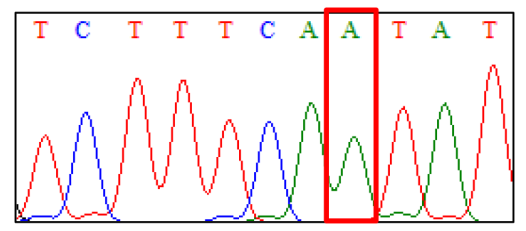

(i)

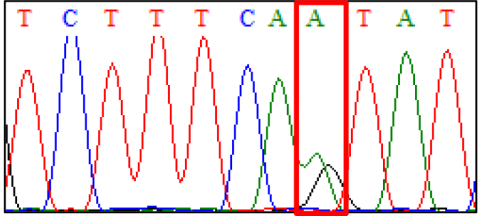

(ii)

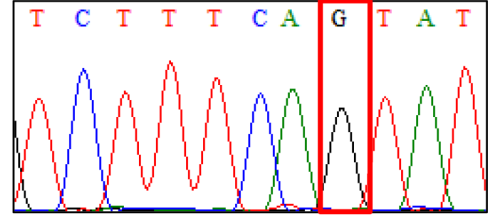

(iii)

Fig. 2 Sequencing results for a CYP3A4*18 and b CYP3A5*. a (i) a homozygous wild type genotype. (ii) a heterozygous genotype. $\mathbf{b}$ (i) a homozygous wild type genotype. (ii) a heterozygous genotype.

(iii) a homozygous variant genotype.

observed for $C Y P 3 A 4^{\star} 18$ polymorphism in both CML patients and normal healthy controls. The genotype frequencies of heterozygous $\left({ }^{*} 1 /{ }^{*} 18\right)$ genotypes were significantly $(p=0.003)$ higher in CML patients $(8.89 \%$ in CML patients vs $2.80 \%$ in normal healthy controls). However, the frequencies of homozygous wild type $\left({ }^{\star} 1 /{ }^{\star} 1\right)$ genotypes were significantly $(p=0.041)$ higher in normal healthy controls $(97.20 \%$ in normal healthy controls vs $91.11 \%$ in CML patients). When the association of genotype with CML susceptibility risk was assessed, the heterozygous $\left({ }^{\star} 1 /{ }^{\star} 18\right)$ genotype of CYP3A4 showed significantly higher risk (OR 3.387; 95\% CI: 1.433-8.007, $p=0.005$ ) for CML development.

Table 1 Hardy-Weinberg Equilibrium test in controls

\begin{tabular}{lcc}
\hline Polymorphisms & Chi square $\left(\boldsymbol{X}^{2}\right)$ & $\boldsymbol{p}$-value \\
\hline CYP3A4*18 & 0.050 & 0.822 \\
CYP3A5*3 $^{*}$ & 0.034 & 0.853 \\
\hline
\end{tabular}

For $C Y P 3 A 5^{\star} 3$ polymorphism, the frequencies of homozygous variant $\left(* 3 /{ }^{*} 3\right)$ genotypes were significantly higher in normal healthy controls $(49.60 \%$ in normal healthy controls vs $24.44 \%$ in CML patients, $p<0.001)$. However, the frequencies of homozygous wild type $\left({ }^{\star} 1 /{ }^{\star} 1\right)$ genotypes were significantly higher in CML patients $(29.63 \%$ in CML patients vs $8.40 \%$ in normal healthy controls) with $p<0.001$. There was no significant difference in the frequencies of heterozygous $\left({ }^{\star} 1 /{ }^{\star} 3\right)$ genotype between cases and controls (45.93\% in CML patients vs $42.00 \%$ in normal healthy controls, $p=0.368$ ). On evaluating the association of genotypes with CML susceptibility risk, the homozygous variant $(\star 3 / * 3)$ and heterozygous $(* 1 / * 3)$ genotypes of $C Y P 3 A 5$ showed significantly lower risk (OR 0.140; 95\% CI: 0.079-0.246, $p<0.001$ and OR $0.310 ; 95 \%$ CI: $0.180-0.535$, $p<0.001$, respectively). 
Table 2 Genotype and allele frequencies of CYP3A4* 18 and CYP3A5*3 in CML patients and normal healthy controls

\begin{tabular}{|c|c|c|c|c|}
\hline \multirow[b]{2}{*}{ SNP (rs number) } & & \multicolumn{3}{|c|}{ Genotype frequencies } \\
\hline & & $\begin{array}{c}\text { CML patients } \\
n=270(\%)\end{array}$ & $\begin{array}{c}\text { Healthy controls } \\
n=250(\%)\end{array}$ & $p$-value \\
\hline \multirow{7}{*}{ CYP3A4*18 (rs28371759) } & Genotype & & & \\
\hline & Homozygous wildtype $\left({ }^{*} 1 /{ }^{*} 1\right)$ & $246(91.11)$ & $243(97.20)$ & $0.041 *$ \\
\hline & Heterozygous $\left({ }^{*} 1 /{ }^{*} 18\right)$ & $24(8.89)$ & $7(2.80)$ & $0.003^{*}$ \\
\hline & Homozygous variant $\left({ }^{*} 18 /{ }^{*} 18\right)$ & - & - & - \\
\hline & Allele & & & \\
\hline & *1 & $516(95.56)$ & $493(98.60)$ & \\
\hline & ${ }^{*} 18$ & $24(4.44)$ & $7(1.40)$ & $0.004^{*}$ \\
\hline \multirow{7}{*}{ CYP3A5*3 (rs776746) } & Genotype & & & \\
\hline & Homozygous wildtype $\left({ }^{*} 1 /{ }^{*} 1\right)$ & $80(29.63)$ & $21(8.40)$ & $<0.001 *$ \\
\hline & Heterozygous $\left({ }^{*} 1 /{ }^{*} 3\right)$ & $124(45.93)$ & $105(42.00)$ & 0.594 \\
\hline & Homozygous variant $\left({ }^{*} 3 /{ }^{*} 3\right)$ & $66(24.44)$ & $124(49.60)$ & $<0.001 *$ \\
\hline & Allele & & & \\
\hline & *1 & $284(52.59)$ & $147(29.40)$ & \\
\hline & *3 & $256(47.41)$ & $353(70.60)$ & $<0.001 *$ \\
\hline
\end{tabular}

${ }^{*} p<0.05$ is statistically significant

Table 3 Genotype frequencies and association of CYP3A4* 18 and CYP3A5*3 polymorphisms with CML susceptibility

\begin{tabular}{|c|c|c|c|c|c|}
\hline \multirow{2}{*}{$\begin{array}{l}\text { SNP } \\
\text { (rs number) }\end{array}$} & \multirow[b]{2}{*}{ Genotype } & \multicolumn{2}{|c|}{ Genotype frequencies } & \multicolumn{2}{|c|}{ Susceptibility risk } \\
\hline & & $\begin{array}{c}\text { CML patients } \\
n=270(\%)\end{array}$ & $\begin{array}{l}\text { Healthy controls } \\
n=250(\%)\end{array}$ & OR $(95 \% \mathrm{CI})$ & $p$-value \\
\hline \multirow{3}{*}{$\begin{array}{l}\text { CYP3A4*18 } \\
(\text { rs28371759) }\end{array}$} & Homozygous wildtype $\left({ }^{*} 1{ }^{*} 1\right)$ & $246(91.11)$ & $243(97.20)$ & 1.000 & - \\
\hline & Heterozygous $\left({ }^{*} 1 /{ }^{*} 18\right)$ & $24(8.89)$ & $7(2.80)$ & $3.387(1.433-8.007)$ & $0.005^{*}$ \\
\hline & Homozygous variant $\left({ }^{*} 18 /{ }^{*} 18\right)$ & - & - & - & - \\
\hline \multirow{3}{*}{$\begin{array}{l}\text { CYP } 3 A 5^{*} 3 \\
\text { (rs776746) }\end{array}$} & Homozygous wildtype $\left({ }^{*} 1 /{ }^{*} 1\right)$ & $80(29.63)$ & $21(8.40)$ & 1.000 & - \\
\hline & Heterozygous $(* 1 / * 3)$ & $124(45.93)$ & $105(42.00)$ & $0.310(0.180-0.535)$ & $<0.001 *$ \\
\hline & Homozygous variant $\left(* 3 /{ }^{*} 3\right)$ & $66(24.44)$ & $124(49.60)$ & $0.140(0.079-0.246)$ & $<0.001 *$ \\
\hline
\end{tabular}

${ }^{*} p<0.05$ is statistically significant

In the present study, we also evaluated the association of the polymorphic genotypegenotype combinations (Table 4) of $C Y P 3 A 4^{\star} 18$ and $C Y P 3 A 5^{\star} 3$ with $\mathrm{CML}$ susceptibility risk. The results showed that the combinations of wild type genotype of $C Y P 34^{\star} 18$ and heterozygous genotype of $C Y P 3 A 5^{\star} 3$ as well as combination of wild type genotype of $C Y P 3 A 4^{\star} 18$ and homozygous variant genotype of $C Y P 3 A 5^{\star} 3$ posed a significantly lower risk for $\mathrm{CML}$ development.

\section{DISCUSSION}

Majority of cancers develop as a result of interaction between environmental factors and hosts's inherent genetic susceptibility. Although $B C R-A B L$ fusion is an essential mechanism needed, other predisposing cellular or molecular events are also required for chronic myeloid leukaemogenesis. CYP450 enzymes are involved in activation of a number of exogenous pro-carcinogens into highly reactive electrophilic carcinogenic 
Table 4 Association of genotype combinations of CYP3A4* 18 and CYP $3 A 5^{*} 3$ with CML susceptibility risk

\begin{tabular}{|c|c|c|c|c|c|}
\hline \multicolumn{2}{|c|}{ Polymorphisms combinations } & $\begin{array}{c}\text { CML patients } \\
n=270(\%)\end{array}$ & $\begin{array}{c}\text { Normal healthy } \\
\text { controls } \\
\mathbf{n = 2 5 0}(\%)\end{array}$ & OR $(95 \% \mathrm{CI})$ & $p$-value \\
\hline CYP3A4*18 & CYP $3 A 5 * 3$ & & & & \\
\hline Wild type $\left({ }^{*} 1 /{ }^{*} 1\right)$ & Wild type $\left(* 1 /{ }^{*} 1\right)$ & $74(27.41)$ & $20(8.00)$ & 1.000 & - \\
\hline Wild type $\left({ }^{*} 1 /{ }^{*} 1\right)$ & Heterozygous $\left({ }^{*} 1 /{ }^{*} 3\right)$ & $109(40.37)$ & $102(40.80)$ & $\begin{array}{c}0.289 \\
(0.164-0.507)\end{array}$ & $<0.001 *$ \\
\hline Wild type $\left({ }^{*} 1 /{ }^{*} 1\right)$ & Variant $(* 3 / * 3)$ & $61(22.59)$ & $121(48.40)$ & $\begin{array}{c}0.136 \\
(0.076-0.244)\end{array}$ & $<0.001 *$ \\
\hline Heterozygous $\left({ }^{*} 1 /{ }^{*} 18\right)$ & Wild type $\left({ }^{*} 1 /{ }^{*} 1\right)$ & $6(2.22)$ & $1(0.40)$ & $\begin{array}{c}1.622 \\
(0.184-14.258)\end{array}$ & 0.663 \\
\hline Heterozygous $\left({ }^{*} 1 /{ }^{*} 18\right)$ & Heterozygous $\left({ }^{*} 1 /{ }^{*} 3\right)$ & $14(5.19)$ & $3(1.20)$ & $\begin{array}{c}1.261 \\
(0.330-4.823)\end{array}$ & 0.743 \\
\hline Heterozygous $\left({ }^{*} 1 /{ }^{*} 18\right)$ & Variant $(* 3 / * 3)$ & $6(2.22)$ & $3(1.20)$ & $\begin{array}{c}0.541 \\
(0.124-2.354)\end{array}$ & 0.412 \\
\hline Variant $\left({ }^{*} 18 /{ }^{*} 18\right)$ & Wild type $\left({ }^{*} 1 /{ }^{*} 1\right)$ & - & - & - & - \\
\hline Variant $\left({ }^{*} 18 /{ }^{*} 18\right)$ & Heterozygous $\left({ }^{*} 1 /{ }^{*} 3\right)$ & - & - & - & - \\
\hline Variant $\left({ }^{*} 18 /{ }^{*} 18\right)$ & Variant $\left({ }^{*} 3 /{ }^{*} 3\right)$ & - & - & - & - \\
\hline
\end{tabular}

${ }^{*} p<0.05$ is statistically significant

molecules (Indulski and Lutz, 2000). These electrophiles can bind to DNA and form adducts leading to mutations in protooncogenes and tumor suppressor genes, and initiate carcinogenesis if not repaired by the DNA repair system. Genetic polymorphisms have emerged in recent years as important determinants of disease susceptibility and severity. Genetic variations in genes encoding Phase I and Phase II xenobiotic enzymes have been linked with the variation in susceptibility of different individuals/ ethnic groups/populations towards leukaemia (Jamil and Reddy, 2007). CYP3A family has been found to be abundantly expressed in the human liver and is the predominant subfamily involved in the metabolism of clinically used drugs which participate in the metabolic activation and metabolism of several carcinogens. Interindividual variation in $C Y P 3 A$ activity might have a major impact on pharmacokinetics and metabolism of majority of xenobiotics. $C Y P 3 A 4$ and $C Y P 3 A 5$ acts as synergistic defense mechanism against the intrusion of xenobiotics. To the best of available knowledge, this is the first study investigating the contribution of $C Y P 3 A 4^{\star} 18$ and $C Y P 3 A 5^{\star} 3$ polymorphisms in modulating the susceptibility risk in Malaysian CML patients.

CYP3A4 enzymes are involved in the detoxification of foreign chemicals (such as carcinogens) and the metabolism of drugs. In earlier studies, the variant allele $C Y P 3 A 4^{\star} 18$ was detected at a frequency of $1.7 \%$ in healthy Korean population (Lee et al., 2007), $2 \%$ in healthy Chinese population (Dai et al., 2001), $1.3 \%$ in healthy Japanese population (Yamamoto et al., 2003) and $2.07 \%$ among Malaysian diabetics (Ruzilawati et al., 2007). In the present study, the frequency of $C Y P 3 A 4^{\star} 18$ variant allele was detected at $4.44 \%$ in Malaysian CML patients and $1.40 \%$ in normal healthy controls. As for $C Y P 3 A 5^{\star} 3$, the variant allele was detected at frequency of $70 \%$ in Singaporean breast cancer ( $\operatorname{Lim}$ et al., 2011), 67\% in healthy Vietnamese subjects (Veiga et al., 2009), $47.41 \%$ in Malaysian CML patients and $70.60 \%$ in normal healthy controls. The allele frequencies of $C Y P 3 A 4^{\star} 18$ and $C Y P 3 A 5^{\star} 3$ were checked and found to be in HWE (Table 1). 
The present study showed that the heterozygous $\left({ }^{\star} 1 /{ }^{\star} 18\right)$ genotype was significantly associated with higher risk (OR 3.387 ; 95\% CI: $1.433-8.007, p=0.005$ ) for CML development. It is reasonable to suggest that polymorphism of $C Y P 3 A 4^{\star} 18$ may act synergistically with the $B C R-A B L$ fusion oncogene in causing CML. Earlier, Kang et al. (2009) reported that codon 293 is located at the start of the highly conserved helix I. Change of a single amino acid, L293P, at the beginning of helix I influences the overall protein structure and this leads to the modification of the arrangement of substrate recognition sites (SRS) regions, the important sites for substrate recognition, and substrate access to the active site (Kang et al., 2009). The conformational change in $C Y P 3 A 4^{\star} 18$ may lead to alteration of metabolic activity, depending on substrate types (Maekawa et al., 2010). So, it is reasonable to suggest that individuals with the heterozygous genotype $\left({ }^{\star} 1 /{ }^{\star} 18\right)$ of CYP3A4 have decreased ability to detoxify carcinogens and have a greater risk of developing CML, compared to the individuals who have homozygous wild type genotype which efficiently detoxifies the carcinogens. A study reported that polymorphism of $C Y P 3 A 4^{\star} 18$ was not associated with pediatric tuberculosis risk in Chinese population (Feng et al., 2012).

On the contrary, the homozygous variant $\left(\star^{*} /{ }^{*}\right)$ and heterozygous $\left({ }^{*} 1 /{ }^{*}\right)$ genotypes of $C Y P 3 A 5^{\star} 3$ were found to be associated with a significantly lower risk for CML susceptibility with OR $0.140 ; 95 \%$ CI: $0.079-0.246, p<0.001$ and OR $0.310 ; 95 \%$ CI: $0.180-0.535, p<0.001$, respectively. Since the frequency of variant genotype $\left({ }^{*} 3 /{ }^{\star} 3\right)$ was higher in normal healthy controls $(49.60 \%$ vs $24.44 \%)$, it is suggested that this variant allele may protect an individual from the harmful effects of carcinogens thereby lowering the CML susceptibility risk. Our study is in concordance with a study in Taiwanese population by Liu et al. (2002) and in a North Indian population by Bajpai et al. (2010) which showed that the polymorphism of $C Y P 3 A 5^{\star} 3$ was not associated with the risk of CML development. However, our study is contradictory with another Indian study by Sailaja et al. (2010), which found association of $C Y P 3 A 5^{\star} 3$ polymorphism with higher risk of CML development. In a different study, homozygous variant $(* 3 / \star 3$ or GG) genotype of CYP3A5 (6986A > G) was found to be significantly associated with increased susceptibility to ischemic stroke and atherothrombotic events in stroke patients by interacting with $A L O X 5 A P-S G 12 S 114 \mathrm{~A}>\mathrm{T}$ (Yi et al., 2015). Other than that, a study by Feng et al. (2012) reported that the variants of $C Y P 3 A 56986 \mathrm{~A}>\mathrm{G}$ contributed to protection from pediatric tuberculosis in China.

Although some polymorphisms do not show any significant associations when acting individually, risk association may still remain possible when the genotypes and alleles of different polymorphisms are analysed in combination form. When the genotype combinations of $C Y P 3 A 4^{\star} 18$ and $C Y P 3 A 5^{\star} 3$ were assessed, the combinations of $C Y P 3 A^{\star} 1 /{ }^{\star} 1+C Y P 3 A 5^{\star} 1 /{ }^{\star} 3$ and $C Y P 3 A 4^{\star} 1 /{ }^{\star} 1+C Y P 3 A 5^{\star} 3 /{ }^{\star} 3$ showed significantly lower risk (OR 0.289; 95\% CI: $0.164-0.507, p<0.001$ and OR 0.136 ; $95 \%$ CI: $0.076-0.244, p<0.001$, respectively) for CML susceptibility. Although the heterozygous genotype of $C Y P 3 A 4^{\star} 18$ previously showed higher risk for development of CML, no significant association with CML susceptibility risk was detected when the genotype was in combination with $C Y P 3 A 5^{\star} 3$. It can be suggested that individuals who have $C Y P 3 A 5^{\star} 3$ polymorphism may have lower risk in development of CML. However, the mechanism on how these combinations can lower CML susceptibility risk is unclear. Hence, further studies may be needed to give a clearer explanation on this aspect.

The results of the present study are in agreement as well as in contradiction with few other studies. This could be due to difference in the genetic background of study subjects, variation in sample size and study 
design, variation and intensity in exposure to different types of environmental carcinogens and gene-gene interactions. Our study has few limitations. Other risk factors such as exposure to carcinogens or lifestyle habits which might affect the polymorphisms of $C Y P 3 A 4^{\star} 18$ and $C Y P 3 A 5^{\star} 3$ in association with CML development was not accounted in this study. Other than that, study on correlation of variant allele with expression of $C Y P 3 A 4^{\star} 18$ and $C Y P 3 A 5^{\star} 3$ gene that is linked to the development of CML also was not investigated. The results derived by taking into consideration of all these limitations, might give a better explanation for CML susceptibility.

\section{CONCLUSION}

The results prompt us to suggest that genetic variations of $C Y P 3 A 4^{\star} 18$ may contribute a higher risk whereas $C Y P 3 A 5^{\star} 3$ polymorphism might contribute to a lower risk for CML susceptibility in Malaysian subjects.

\section{ACKNOWLEDGEMENTS}

This study was supported by Universiti Sains Malaysia Research University (RUI) Grant no: $1001 / \mathrm{PPSP} / 812103$.

\section{REFERENCES}

Al-Achkar W, Aljapawe A, Almedani S, Liehr T, Wafa A (2013). A novel cytogenetic abnormality $\mathrm{t}(7 ; 8)(\mathrm{p} 11.2: \mathrm{q} 11.2)$ and $\mathrm{a}$ four-way Philadelphia translocation in an imatinib mesylate-resistant chronic myeloid leukemia patient. Oncol Lett, 5(2): 617620. https://doi.org/10.3892/ol.2012.1037

Bajpai P, Tripathi AK, Agrawal D (2010). Genetic polymorphism of CYP3A5 in Indian chronic myeloid leukemia patients. Mol Cell Biochem, 336(1-2): 49-54. https://doi.org/10.1007/s1 1010-009-0268-1
Biernaux C, Loos M, Sels A, Huez G, Stryckmans P (1995). Detection of major bcr-abl gene expression at a very low level in blood cells of some healthy individuals. Blood, 86(8): 3118-3122.

Bose S, Deininger M, Gora-Tybor J, Goldman JM, Melo JV (1998). The presence of typical and atypical BCR-ABL fusion genes in leukocytes of normal individuals: Biologic significance and implications for the assessment of minimal residual disease. Blood, 92(9): 3362-3367.

Dai D, Tang J, Rose R, Hodgson E, Bienstock RJ, Mohrenweiser HW et al. (2001). Identification of variants of CYP3A4 and characterization of their abilities to metabolize testosterone and chlorpyrifos. F Pharmacol Exp Ther, 299(3): 825-831.

Feng WX, Liu F, Gu Y, Jiao WW, Sun L, Xiao J et al. (2012). Functional polymorphisms in CYP2C19 \& CYP3A5 genes associated with decreased susceptibility for paediatric tuberculosis. Indian $\mathcal{F}$ Med Res, 135(5): 642-649.

$\mathrm{Hu}$ YF, He J, Chen GL, Wang D, Liu ZQ, Zhang C et al. (2005). CYP3A5*3 and CYP3A $4{ }^{\star} 18$ single nucleotide polymorphisms in a Chinese population. Clin Chim Acta, 353(1-2): 187-192. https://doi.org/10.1016/j.cccn.2004.11.005

Indulski J, Lutz W (2000). Metabolic genotype in relation to individual susceptibility to environmental carcinogens. Int Arch Occup Environ Health, 73(2): 71-85. https://doi. org/10.1007/PL00007942

Jamil K, Reddy H (2007). Can polymorphisms in genes relate to overall survival in leukemias? Leuk Lymphoma, 48(6): 1070-1071. https:// doi.org/10.1080/10428190701287353 
Kang YS, Park SY, Yim CH, Kwak HS, Gajendrarao P, Krishnamoorthy $\mathrm{N}$ et al. (2009). The CYP3A4*18 genotype in the cytochrome $\mathrm{P} 450$ 3A4 gene, a rapid metabolizer of sex steroids, is associated with low bone mineral density. Clin Pharmacol Ther, 85(3): 312-318. https:// doi.org/10.1038/clpt.2008.215

Lee SJ, Lee SS, Jeong HE, Shon JH, Ryu JY, Sunwoo YE et al. (2007). The CYP3A4*18 allele, the most frequent coding variant in asian populations, does not significantly affect the midazolam disposition in heterozygous individuals. Drug Metab Dispos, 35(11): 2095-2101. https://doi.org/ $10.1124 / \mathrm{dmd} .107 .016733$

Lim JS, Chen XA, Singh O, Yap YS, Ng RC, Wong NS et al. (2011). Impact of CYP2D6, CYP3A5, CYP2C9 and CYP2C19 polymorphisms on tamoxifen pharmacokinetics in Asian breast cancer patients. $\mathrm{Br} \quad \mathcal{F}$ Clin Pharmacol, 71(5): 737-750. https://doi.org/10.1111/j.13652125.2011.03905.x

Liu TC, Lin SF, Chen TP, Chang JG (2002). Polymorphism analysis of CYP3A5 in myeloid leukemia. Oncol Rep, 9(2): 327329.

Maddin N, Husin A, Gan SH, Aziz BA, Ankathil $\mathrm{R}$ (2016). Impact of $C Y P 3 A 4^{\star} 18$ and $C Y P 3 A 5^{\star} 3$ polymorphisms on imatinib mesylate response among chronic myeloid lleukemia patients in Malaysia. Oncol Ther, 4(2): 303-314. https://doi.org/10.1007/ s40487-016-0035-x

Maekawa K, Harakawa N, Yoshimura T, Kim SR, Fujimura Y, Aohara F et al. (2010). CYP3A4* 16 and CYP3A4* 18 alleles found in East Asians exhibit differential catalytic activities for seven CYP3A4 substrate drugs. Drug Metab Dispos, 38(12): 2100-2104. https://doi.org/10.1124/dmd .110 .034140
Nikumbh JV, Wader VY, Kshirsagar SR, Desai SV, Jagtap, Khedkar JK (2012). Adult type-chronic myeloid leukemia in childhood: A case report. $\mathcal{F}$ Krishna Inst Med Sci Univ, 1(1): 113-117.

Rumjanek VM, Vidal RS, Maia RC (2013). Multidrug resistance in chronic myeloid leukemia: How much can we learn from MDR-CML cell lines? Biosci Rep, 33(6): e00081. https://doi.org/10.1042/ BSR20130067

Ruzilawati AB, Suhaimi AW, Gan SH (2007). Genetic polymorphisms of CYP3A4: CYP3A4* 18 allele is found in five healthy Malaysian subjects. Clin Chim Acta, 383(1-2): 158-162. https://doi.org/10 $.1016 /$ j.cca.2007.05.004

Sailaja K, Rao DN, Rao DR, Vishnupriya $S$ (2010). Analysis of CYP $3 A 5^{\star} 3$ and CYP3A $5^{\star} 6$ gene polymorphisms in Indian chronic myeloid leukemia patients. Asian Pac f Cancer Prev, 11(3): 781-784.

Seong SJ, Lim M, Sohn SK, Moon JH, Oh SJ, Kim BS et al. (2013). Influence of enzyme and transporter polymorphisms on trough imatinib concentration and clinical response in chronic myeloid leukemia patients. Ann Oncol, 24(3): 756-760. https://doi.org/10.1093/annonc/mds532

Veiga MI, Asimus S, Ferreira PE, Martins JP, Cavaco I, Ribeiro V et al. (2009). Pharmacogenomics of CYP2A6, CYP2B6, CYP2C19, CYP2D6, CYP3A4, CYP3A5 and MDR1 in Vietnam. Eur $\mathcal{f}$ Clin Pharmacol, 65(4): 355-363. https://doi.org/ 10.1007/s00228-008-0573-8

Yamamoto T, Nagafuchi N, Ozeki T, Kubota $\mathrm{T}$, Ishikawa H, Ogawa $\mathrm{S}$ et al. (2003). CYP3A4*18: It is not rare allele in Japanese population. Drug Metab Pharmacokinet, 18(4): 267-268. https://doi. org/10.2133/dmpk.18.267 
Yi XY, Zhang BA, Wang C, Liao DX, Lin J, Chi LF (2015). Genetic polymorphisms of ALOX5AP and CYP3A5 increase susceptibility to ischemic stroke and are associated with atherothrombotic events in stroke patients. $\mathcal{F}$ Stroke Cerebrovasc Dis, 24(3): 521-529. https://doi.org/10.1016/ j.jstrokecerebrovasdis.2014.09.035
Zheng X, Oancea C, Henschler R, Moore MA, Ruthardt $M$ (2009). Reciprocal $t(9 ; 22)$ ABL/BCR fusion proteins: Leukemogenic potential and effects on B cell commitment. PLoS One, 4(10): e7661. https://doi.org/10 .1371 /journal.pone.0007661 